\title{
Pelayanan Tenaga Administrasi Sekolah Urusan Persuratan dan Pengarsipan Berbasis Teknologi Informasi di SMK se-Kota Payakumbuh
}

\author{
Desi Triana $^{1}$, Rusdinal ${ }^{2}$, Jasrial ${ }^{3}$, Lusi Susanti ${ }^{4}$ \\ 4 \\ Desi Triana ${ }^{1}$, e-mail: trianadesi7@gmail.com \\ Rusdinal ${ }^{2}$, e-mail: rusdinal@fip.unp.ac.id \\ Jasrial ${ }^{3}$, e-mail: jas.rial@yahoo.com \\ Lusi Susanti ${ }^{4}$, e-mail: lusi_mp@yahoo.com
}

${ }^{1}$ Administrasi Pendidikan, Universitas Negeri Padang $1,{ }^{2}$ Administrasi Pendidikan, Universitas Negeri Padang, 2 Administrasi Pendidikan, Universitas Negeri Padang 3, ${ }^{4}$ Administrasi Pendidikan, Universitas Negeri Padang

\begin{abstract}
This research is motivated by the observations and interviews of the authors of several teachers at SMKN 1 Padang that showed that the school administration services for surveying and archiving based on information technology have not been good. The research aims to obtain information on Administrative Personnel Services School of Research Affairs and Information Technology-Based Archiving as seen from the aspects of (1) Physical Evidence, (2) Reliability, (3) Response. This study is descriptive quantitative with a population of all 458 teachers in vocational schools in Payakumbuh City. While the sample size was taken using Slovin formula with a $10 \%$ error rate using Proportional Random Sampling techniques ratified by 82 teachers. The assessment instrument is a Likert scale questionnaire with five alternative answers. The results showed the ministry of administrative personnel services school administration affairs surveying and archiving based on information technology from aspects tangible (physical evidence) with a good category average score of 4.20, school administration services for surveying and archiving based on information technology from reliability aspects (reliability) is in a good position with an average score of 4.09, school administration services survey affairs and information technology-based archiving from responsiveness aspects (responsiveness) has been carried out well at the level of 4.00. From the whole, it can be concluded that the ministry of school administration of research and archiving based on information technology in smk in Payakumbuh City has been carried out well with the acquisition of the number 4.10 .
\end{abstract}

\begin{abstract}
Abstrak
Penelitian ini dilatarbelakangi dari hasil pengamatan dan wawancara penulis terhadap beberapa orang guru di SMKN 1 Padang yang menunjukkan bahwa pelayanan tenaga administrasi sekolah urusan persuratan dan pengarsipan berbasis teknologi informasi belum baik. Penelitian bertujuan untuk mendapatkan informasi mengenai Pelayanan Tenaga Administrasi Sekolah Urusan Persuratan dan Pengarsipan Berbasis Teknologi Informasi yang dilihat dari aspek (1) Bukti Fisik, (2) Kehandalan, (3) Ketanggapan. Pengkajian ini bersifat deskriptif kuantitatif dengan populasi semua sebanyak 458 orang guru yang ada di SMK se-Kota Payakumbuh. Sedangkan besaran sampel diambil menggunakan rumus Slovin dengan tingkat kesalahan 10\% menggunakan teknik Pengambilan Sampel Acak Proporsional Yang diratifikasi sebanyak 82 guru. Instrumen pengkajian ialah angket skala Likert dengan lima alternatif jawaban. Hasil penelitian menunjukkan pelayanan tenaga administrasi pelayanan tenaga administrasi sekolah urusan persuratan dan pengarsipan berbasis teknologi informasi dari aspek Tangible (bukti fisik) dengan kategori baik skor rata-rata 4,20, pelayanan tenaga administrasi sekolah urusan persuratan dan pengarsipan berbasis teknologi informasi dari aspek Reliability (kehandalan) berada pada posisi baik dengan skor rata-rata 4,09, pelayanan tenaga administrasi sekolah urusan persuratan dan pengarsipan berbasis teknologi informasi dari aspek Responsiveness (ketanggapan) sudah terlaksana dengan baik pada taraf 4,00. Dari keseluruhan dapat disimpulkan pelayanan tenaga administrasi sekolah urusan persuratan dan pengarsipan berbasis teknologi informasi di SMK se-Kota Payakumbuh telah terlaksana dengan baik dengan perolehan angka 4,10 .
\end{abstract}

Kata Kunci: Pelayanan, TAS, Teknologi Informasi

How to Cite: Desi Triana 1, Rusdinal 2, Jasrial 3, Susanti, Lusi 4. 2021. Pelayanan Tenaga Administrasi Sekolah Urusan Persuratan dan Pengarsipan Berbasis Teknologi Informasi di SMK se-Kota Payakumbuh. 
Desi Triana 1, Rusdinal 2, Jasrial 3, Susanti, Lusi 4. Pelayanan Tenaga Administrasi Sekolah Urusan Persuratan dan Pengarsipan Berbasis Teknologi Informasi di SMK se-Kota Payakumbuh Journal Educational Administration and Leadership, Vol $(\mathrm{N})$ : $p$ p. $\mathrm{XX}-\mathrm{XX}$, DOI: 10.24036/XXXXXXXXXX-X-XX

\section{Pendahuluan}

Pendidikan adalah hal penting dalam kehidupan dan peradaban manusia. Pendidikan adalah hal yang bersifat berkelanjutan. Mengacu pada (Undang-Undang No. 20 Tentang Sistem Pendidikan Nasional, 2003) tentang sistem pendidikan nasional, fungsi pendidikan sebagaimana yang dibahas dalam pasal 3 yaitu "Pendidikan nasional bertujuan untuk membangun keahlian dan menciptakan karakter serta kemajuan rakyat yang terhormat untuk mencerdaskan kehidupan bangsa, berfungsi mengembangkan kemampuan siswa supaya jadi siswa yang percaya kepada Tuhan Yang Maha Esa, berbudi pekerti, sehat, berpendidikan, cekatan, inovatif, tidak bergantung pada orang lain, dan menjadi manusia yang demokratis serta bertanggung jawab.

Agar tercapainya fungsi dan tujuan pendidikan seperti yang telah dibahas sebelumnya, menjadi tanggung jawab semua personil sekolah, termasuk juga pengajar dan staf tenaga kependidikan. Tenaga kependidikan yang dimaksud disini adalah tenaga administrasi sekolah. Tenaga administrasi sekolah yang kemudian disebut tata usaha (TU). Mereka memang tidak langsung ikut serta dalam proses pembelajaran, namun mereka secara tidak langsung ikut andil dalam keberhasilan sekolah dalam mencapai tujuan pendidikan. Dalam (Pedoman Penyusunan Standar Pelayanan Minimal Penyelenggaraan Persekolahan Bidang Pendidikan Dasar Dan Menengah, 2001) Tenaga Administrasi Sekolah yaitu SDM di sekolah yang terlibat tidak langsung dalam proses pembelajaran tetapi juga mendorong kesuksesan dalam kegiatan manajemen organisasi. Tenaga Administrasi sendiri terdiri dari Kepala Tenaga Administrasi Sekolah, Pelaksana Urusan yang mencakup : Kegiatan Manajemen Karyawan; Kegiatan Manajemen Keuangan; Urusan Manajemen Sarana Prasarana; Urusan Manajemen Humas; Pelaksana Urusan Manajemen Persuratan dan Kearsipan; Pelaksana Urusan i Kesiswaan; Pelaksana Urusan Kurikulum; Urusan Manajemen Umum untuk SD/MI/SDLB, dan Petugas Khusus, terdiri: Satpam; Tukang Bersih-bersih; Sopir; dan pembantu (pesuruh).

Pelaksana Administrasi Persuratan dan Kearsipan memiliki perananan penting untuk pelayanan administrasi sekolah. Pelayanan yang dilakukan oleh tenaga administrasi urusan persuratan dan kersipan membutuhkan teknologi informasi. Teknologi Informasi era ini mengalami perkembangan yang begitu cepat. Sejalan bersama perkembangan teknologi informasi yang mendunia berpengaruh semua bagian kehidupan baik bidang perekonomian, sosial, seni, dan budaya bahkan dalam kehidupan pendidikan. Perkembangan teknologi merupakan hal yang tidak bisa dihindari di kehidupan ini, karena perkembangan teknologi berjalan seiring dengan perkembangan ilmu pengetahuan. Teknologi informasi pun memberikan pengaruh yang besar bagi tenaga administrasi sekolah urusan persuratan dan pengarsipan dalam memberikan pelayanan bagi masyarakat sekolah baik kepada guru maupun kepada para siswa. Sebagaimana dijelaskan oleh (Sunyoto, 2014) tugas dari tenaga administrasi sekolah urusan persuratan dan pengarsipan ialah mencatat persuratan yang masuk dan yang keluar, membuat persuratan kantor, memberikan surat kantor kepada instansi yang berkait, dan menjaga surat yang telah diarsipkan.

Namun dalam kenyataannya masih banyak tenaga administrasi sekolah urusan persuratan dan pengarsipan yang belum dimanfaatkan secara baik teknologi informasi untuk mempermudah melakukan pekerjaannya terutama dalam mengarsipkan berkas-berkas penting. Ini terlihat dari fenomena yang penulis temukan di sebuah SMK Negeri di Kota Padang. Adapun fenomena tersebut adalah : masih terdapat tenaga administrasi sekolah urusan persuratan dan pengarsipan yang masih melakukan pengarsipan secara manual, sehingga ketika siapapun yang membutuhkan berkas tertentu, tenaga administrasi sekolah kesulitan dalam mencarinya dan lama dalam memberikan pelayanan. Hal ini terkait dengan penelitian yang dilakuan oleh Soesilo pada tahun 2016. Soesilo melakukan penelitian tentang optimalisasi pengelolaan kearsipan melalui E-Arsip direktorat jenderal guru dan tenaga kependidikan. Dalam penelitiannya, dapat diketahui bahwa terobosan melalui inovasi dalam bidang teknologi informasi mendorong untuk menciptakan media atau mengelola arsip secara modern, yaitu memadukan sistem kearsipan konvensional dengan kemajuan teknologi informasi. Pengembangan Aplikasi E-Arsip adalah salah satu tawaran solusi untuk mengatasi permasalahan dalam pengelolaan arsip. Dikarenakan pengarsipan berkas masih dilakukan dengan cara manual banyak berkas-berkas yang sulit untuk ditemukan. Ini terjadi karena terbatasnya fasilitas yang menunjang untuk menggunakan teknologi juga dikarenakan masih sulitnya karyawan administrasi persuratan untuk memanfaatkan teknologi. Kenyataan tersebut akan mempengaruhi kualitas pelayanan yang dilakukan oleh karyawan administrasi sekolah khususnya pelaksana urusan persuratan pengarsipan. Sedangkan untuk menghadapi kemajuan teknologi informasi sekarang dibutuhkan skill atau kemampuan yang lebih baik dan sebisa mungkin memanfaatkan teknologi. 
Desi Triana 1, Rusdinal 2, Jasrial 3, Susanti, Lusi 4. Pelayanan Tenaga Administrasi Sekolah Urusan Persuratan dan Pengarsipan Berbasis Teknologi Informasi di SMK se-Kota Payakumbuh

\section{Metode Penelitian}

Pengkajian ini tergolong pengkajian deskriptif kuantitatif. Sesuai pendapat (Arikunto, 2010) penelitian gambaran merupakan pengkajian yang bertujuan untuk melihat peristiwa, kondisi, situasi, peristiwa, dan sebagainya nan hasilnya dijelaskan ke bentuk informasi pengkajian. Jumlah populasi pengkajian ini berjumlah 458 orang guru yang ada di Sekolah Menengah Kejuruan se-Kota Payakumbuh. Yang kemudian diambil partisipan yang berjumlah 82 orang. Pengambilan partisipan ditetapkan memakai rumus slovin dengan tingkat kesalahan 10\% dengan teknik Stratified Proportional Random sampling (Noor, 2011) Instrumen penelitian menggunakan angket dengan model skala Likert yang telah diujicobakan guna mendapatkan validitas dan reliabilitas instrumen tersebut. Dalam pengkajian ini menggunakan Rumus rata-rata (mean).

\section{Hasil dan Pembahasan}

Hasil dan pembahasan pengkajian tentang pelayanan tenaga administrasi sekolah urusan persuratan dan pengarsipan berbasis teknologi informasi di SMK se-Kota Payakumbuh ini dapat dilihat dari masing-masing indikator yaitu:

\subsection{Tangible (Bukti Fisik)}

Hasil dari pengumpulan data dan pembahasan tentang bukti fisik dalam pelayanan tenaga administrasi sekolah urusan persuratan dan pengarsipan berbasis teknologi informasi di SMK se-Kota payakumbuh bisa ditilik dalam tabel 1 dibawah ini:

Tabel 1. Penjelasan Data Pelayanan Tenaga Administrasi Sekolah Urusan Persuratan dan Pengarsipan Berbasis Teknologi Informasi di SMK se-Kota Payakumbuh yang dilihat dari aspek Tangible

\begin{tabular}{|l|l|l|l|}
\hline No & Sub Indikator Tangible (Bukti Fisik) & Standar & Kriteria \\
\hline 1. & Fasilitas & 4,26 & Baik \\
\hline 2. & Perlengkapan & 4,14 & Baik \\
\hline & Rata-rata & 4,20 & Baik \\
\hline
\end{tabular}

Tangible pelayanan tenaga administrasi sekolah urusan persuratan dan pengarsipan berbasis teknologi informasi di SMK se-Kota payakumbuh secara umum telah berjalan baik dengan perolehan angka 4.20. Berdasarkan tabel 1, dalam aspek tangible pada fasilitas pelayanan dengan mendapatkan skor rata-rata tertinggi yaitu 4,26 berada pada kategori baik dan pada perlengkapan pelayanan mendapatkan skor ratarata terendah 4.14 berada pada kategori baik.

Sesuai dengan pendapat Abubakar (2000:173) perlengkapan merupakan suatu yang dibutuhkan dalam setiap organisasi, baik organisasi pemerintahan atau organisasi swasta. Tujuannya untuk bisa digunakan untuk melakukan tugas kantor agar berjalan baik dan dapat diselesaikan cepat dan tepat, setara yang diinginkan instansi tersebut. Dari teori yang ada, jelas terlihat pelayanan tenaga administrasi sekolah urusan persuratan dan pengarsipan berbasis teknologi informasi di sekolah ditinjau dari indikator Tangible belum memenuhi Harapan dari standar yang telah ditetapkan.

3.2. Reliability (Kehandalan)

Hasil dari pengumpulan data dan pembahasan tentang kehandalan dalam pelayanan tenaga administrasi sekolah urusan persuratan dan pengarsipan berbasis teknologi informasi di SMK se-Kota payakumbuh bisa ditilik pada tabel 2 dibawah ini:

Tabel 2. Pelayanan Tenaga Administrasi Sekolah Urusan Persuratan dan Pengarsipan Berbasis Teknologi Informasi di SMK se-Kota Payakumbuh yang dilihat dari aspek Kehandalan

\begin{tabular}{|r|l|l|l|}
\hline \multicolumn{1}{|l|}{ No } & Sub Indikator (Kehandalan) & Standar & Kriteria \\
\hline 1. & Kesiapan Pelayanan & 4,16 & Baik \\
\hline 2. & Kemampuan Pelayanan & 4,09 & Baik \\
\hline 3. & Ketepatan Pelayanan & 4,02 & Baik \\
\hline & Rata-rata & 4,09 & Baik \\
\hline
\end{tabular}

Pelayanan Tenaga Administrasi Sekolah Urusan Persuratan dan Pengarsipan Berbasis Teknologi Informasi di SMK se-Kota Payakumbuh yang dilihat dari aspek Reliability secara umum telah terealisasikan baik dengan perolehan angka 4,09. Berdasarkan tabel 2, dalam aspek Reliability pada tahap 
Desi Triana 1, Rusdinal 2, Jasrial 3, Susanti, Lusi 4. Pelayanan Tenaga Administrasi Sekolah Urusan Persuratan dan Pengarsipan Berbasis Teknologi Informasi di SMK se-Kota Payakumbuh

kesiapan pelayanan dengan mendapatkan skor nilai tertinggi yaitu 4,16 berada pada kategori baik dan pada tahap ketepatan pelayanan mendapatkan skor rata-rata terendah 4,02 berada pada kategori baik.

Kemungkinan penyebab rendahnya skor rata-rata pada sub indikator ketepatan pelayanan disebabkan karena petugas belum memberikan pelayanan tepat waktu. Oleh sebab itu petugas TU hendaknya memberikan pelayanan tepat waktu dan tepat sasaran.

Secara keseluruhan pelayanan tenaga administrasi sekolah urusan persuratan dan pengarsipan berbasis teknologi informasi di sekolah dalam aspek Reliability mendapat skor rata-rata 4,09 dengan kategori baik. Artinya pelayanan tenaga administrasi sekolah urusan persuratan dan pengarsipan berbasis teknologi informasi di sekolah dalam aspek Reliability sudah terlaksana dengan baik. Namun masih perlu perbaikan dalam memberikan pelayanan yang tepat. Menurut (Parasuraman, 2001) Reliability atau kehandalan adalah kemampuan demi memberikan bantuan yang dijanjikan dengan tepat. (Sunyoto, 2014) keandalan dari anggota organisasi dalam membagikan bantuan sangat dibutuhkan agar menyongsong gerak dinamika kerja yang terus bergulir menuntut kualitas layanan yang tinggi sesuai kehandalan individu pegawai.

\subsection{Responsiveness}

Data Pelayanan Tenaga Administrasi Sekolah Urusan Persuratan dan Pengarsipan Berbasis Teknologi Informasi di SMK se-Kota Payakumbuh yang dilihat dari aspek Responsiveness bisa ditilik pada tabel 3 dibawah ini:

Tabel 3. Pelayanan Tenaga Administrasi Sekolah Urusan Persuratan dan Pengarsipan Berbasis Teknologi Informasi di SMK se-Kota Payakumbuh yang dilihat dari aspek Responsiveness

\begin{tabular}{|c|l|l|l|}
\hline No & $\begin{array}{l}\text { Sub Indikator Responsiveness } \\
(\text { Ketanggapan) }\end{array}$ & Standar & Kriteria \\
\hline 1. & Pelayanan Tanggap & 4,01 & Baik \\
\hline 2. & Pelayanan Cepat & 3,98 & Baik \\
\hline & Rata-rata & 4,00 & Baik \\
\hline
\end{tabular}

Kemungkinan penyebab rendahnya rata-rata skor item pelayanan cepat dalam pelayanan adalah petugas belum bisa memberikan pelayanan yang diinginkan oleh guru dengan cepat karena keterbatasan petugas baik dalam ilmu maupun tenaga. Menurut Zeythaml et al. (Li, 2009), Responsiveness adalah kecepatan pelayanan dengan menggunakan media atau sarana dalam pelayanan meliputi waktu kerja serta kecepatan respon dari penyedia layanan maupun penerima layanan.

Jadi dapat diketahui bahwa hasil rata-rata skor Pelayanan Tenaga Administrasi Sekolah Urusan Persuratan dan Pengarsipan Berbasis Teknologi Informasi di SMK se-Kota Payakumbuh yang dilihat dari aspek responsiveness secara keseluruhan sudah tinggi hal ini perlu dipertahankan oleh pihak sekolah terutama tenaga administrasi sekolah urusan persuratan dan pengarsipan dalam memberikan pelayanan berbasis teknologi informasi.

\section{Kesimpulan}

Berdasarkan perolehan riset yang telah dijelaskan pada bagian sebelumnya, mengenai Pelayanan Tenaga Administrasi Sekolah Urusan Persuratan dan Pengarsipan Berbasis Teknologi Informasi di SMK seKota Payakumbuh dapat ditarik kesimpulan bahwa Pelayanan Tenaga Administrasi Sekolah Urusan Persuratan dan Pengarsipan Berbasis Teknologi Informasi di SMK se-Kota Payakumbuh dilihat dari indikator Tangible (Bukti Fisik) berdasarkan skor rata-rata yaitu 4,20. Perolehan ini berada pada tingkatan Baik. keadaan ini berarti Pelayanan Tenaga Administrasi Sekolah Urusan Persuratan dan Pengarsipan Berbasis Teknologi Informasi di SMK se-Kota Payakumbuh yang dilihat dari aspek bukti fisik telah terlaksana dengan baik. Pelayanan Tenaga Administrasi Sekolah Urusan Persuratan dan Pengarsipan Berbasis Teknologi Informasi di SMK se-Kota Payakumbuh yang dilihat dari indikator Reability (Kehandalan) berdasarkan skor rata-rata yaitu 4,09. Perolehan ini berada pada tingkatan Baik. Kejadian ini berarti Pelayanan Tenaga Administrasi Sekolah Urusan Persuratan dan Pengarsipan Berbasis Teknologi Informasi di SMK se-Kota Payakumbuh yang dilihat dari aspek kehandalan telah terlaksana dengan baik. Pelayanan Tenaga Administrasi Sekolah Urusan Persuratan dan Pengarsipan Berbasis Teknologi Informasi di SMK se-Kota Payakumbuh yang dilihat dari indikator Responsiveness ( Ketanggapan ) berdasarkan skor rata-rata yaitu 4,00. Perolehan ini berada pada tingkatan Baik. Keadaan ini berarti Pelayanan Tenaga Administrasi Sekolah Urusan Persuratan dan Pengarsipan Berbasis Teknologi Informasi di SMK se-Kota Payakumbuh yang dilihat dari aspek ketanggapan telah terlaksana dengan baik. Pelayanan Tenaga Administrasi Sekolah Urusan Persuratan dan Pengarsipan 
Desi Triana 1, Rusdinal 2, Jasrial 3, Susanti, Lusi 4. Pelayanan Tenaga Administrasi Sekolah Urusan Persuratan dan Pengarsipan Berbasis Teknologi Informasi di SMK se-Kota Payakumbuh

Berbasis Teknologi Informasi di SMK se-Kota Payakumbuh secara umum tergolong dalam kelompok baik dengan taraf jangkauan skor 4,10.

\section{Daftar Rujukan}

Arikunto, S. (2010). Prosedur Penelitian: Suatu Pendekatan Praktik. Rineka Cipta.

Pedoman Penyusunan Standar Pelayanan Minimal Penyelenggaraan Persekolahan Bidang Pendidikan Dasar dan Menengah, 053/U/2001 (2001).

Li, H. (2009). Proposed Scale for Measuring E-Service Quality. International Journal of Science and Technology, 7 (2).

Noor, J. (2011). Metodologi Penelitian. Prenadamedia Group.

Parasuraman, A. V. (2001). (Diterjemahkan oleh Susanto) DeliVering Quality Service. The Free Press.

Sunyoto, D. (2014). Konsep Dasar Riset Pemasaran dan Perilaku konsumen. Kanisius.

Undang-Undang No. 20 tentang Sistem Pendidikan Nasional, (2003). 


\title{
Title Written with the font Time New Roman 15pt (Word: Indonesian); Title of the manuscript; written in English; font Calisto MT; size15; one room; left leveling; attract readers and present the main findings of the study
}

Author name 1, Author name 2

${ }^{1}$ Affiliations $1,{ }^{2}$ Affiliations 2

Author ${ }^{1}$, e-mail: author@email.xx

*Author ${ }^{2}$, e-mail: author@email.xx

\begin{abstract}
The abstract is to be in fully-justified italicized text, at the top of the paper with single column as it is here, below the author information. Use the word "Abstract" as the title, in 10-point Times, boldface type, left relative to the column, initially capitalized. The abstract is to be in 10-point, singlespaced type, and up to 200 words in length. Leave two blank lines after the abstract or list three to five keywords related to the articles, then continued with abstract in bahasa Indonesia.
\end{abstract}

\begin{abstract}
Abstrak
Isi abstrak harus merangkum ringkasan ruang lingkup, tujuan, metode, data, hasil dan kesimpulan utama dari tulisan. Penulisan abstrak dalam bahasa Indonesia ditulis dengan rata kiri-kanan, sesudah abstrak dalam bahasa Inggris, dengan satu spasi dan satu kolom. Kata "Abstrak" sebagai judul ditulis dalam huruf Times 10-point, tebal, rata kiri, dengan huruf pertama dikapitalkan. Teks abstrak ditulis dengan huruf Times 10-point, satu spasi, sampai lebih kurang 250 kata. Sesudah abstrak bahasa Indonesia tuliskan kata kunci dari makalah tersebut dalam daftar kata kunci. Kemudian dilanjutkan dengan teks utama makalah.
\end{abstract}

Keywords: keywords are written in 5 words which should be a subset of the paper's title, written in lowercase except for abbreviations, and separated by comma punctuation between words

How to Cite: Author 1, and Author 2. Year. Title Manuscript. Journal Educational Administration and Leadership, Vol (N): pp. XX-XX, DOI: 10.24036/XXXXXXXXXX-X-XX

This is an open access article distributed under the Creative Commons 4.0 Attribution License, which permits unrestricted use, distribution, and reproduction in any medium, provided the original work is properly cited. (C2020 by author.

\section{Introduction}

The following is a guide to writing research paper in the Jurnal Educational Administration and Leadership published by the professional organization. The manuscript is an unpublished text and the authors are fully responsible for the contents of the manuscript. [1,2].

The article should consist of: 1 . Introduction, 2. Research Method (including analysis, architecture, methods used to solve problems, implementation), 3. Results and Discussion, 4. Conclusion, 5. Acknowledgments (if any) and List of Reference.

The content of the introduction is the answer to the question [3-7]: (1). Background, (2). Brief Literature Review, (3). The reason of this study and (4). Question of purpose.

\section{Metode Penelitian}

Explain the method of preparation and characterization techniques used. Describe briefly, but remain accurate as size, volume, replication and workmanship techniques. For the new method should be explained in detail so that other researchers can reproduce the experiment. While the established method can be explained by quoting a reference. 
Desi Triana 1, Rusdinal 2, Jasrial 3, Susanti, Lusi 4. Pelayanan Tenaga Administrasi Sekolah Urusan Persuratan dan Pengarsipan Berbasis Teknologi Informasi di SMK se-Kota Payakumbuh

\subsection{The Length of the Paper}

The manuscript is written in A4 paper size with a minimum page size of 6 pages, maximum of 15 pages, including tables and drawings, and with reference to the writing procedure as set forth in this paper.

The formula is clearly written using an equation with an index like the following example

$\Delta \mathrm{F}=-2,3 \times 10^{\wedge} 6 \times \mathrm{F}^{\wedge} 2 \Delta \mathrm{M} / \mathrm{A}$

\subsection{Paper Organization}

The title should be clear and concise. Author's name and their affiliation as written above. The author's name is clearly written without a title. Heading numbering uses Arabic system with sub-heading up to 3 levels

2.3. Tables

Tables should be numbered in the order of presentation (Table 1, etc.). Table titles are written on the table with the center justified. The font used is $8 \mathrm{pt}$ in both the title of the table and the contents of the table. Tables should be referenced in the text.

Tabel 1.Tabel Software dan Hardware Pendukung

\begin{tabular}{lll}
\hline Product & Server & Client \\
\hline Clementine & Solaris 2.X & X Windows \\
Darwin & Solaris 2.X & Windows NT \\
PRW & Data on & Windows NT \\
\hline
\end{tabular}

\subsection{Figures}

Gambar diberi nomor sesuai urutan presentasi (Gambar.1, dst.). Judul gambar diletakkan dibawah gambar dengan posisi tengah (centre justified). Font yang dipakai dalam judul gambar berukuran 8pt. Gambar harus diacu dan dirujuk dalam text.

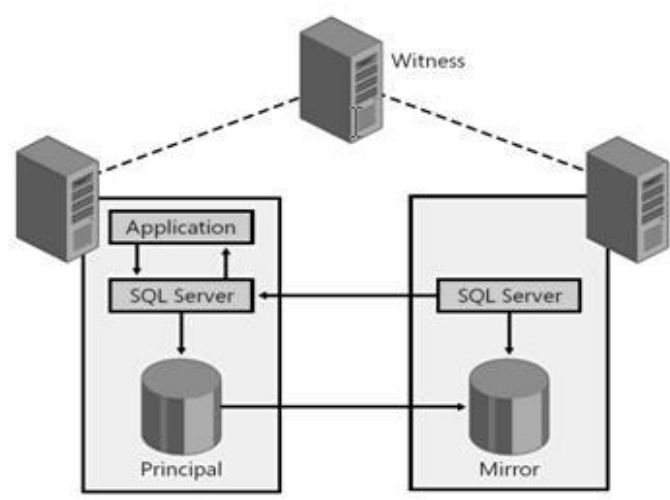

Figure 1. Database Mirroring Architecture

\subsection{Reference}

Reference should be written in the IEEE Referencing Standard system. Everything listed in the reference should be referenced in the text.

\section{Result and Discussion}

The results are written based on a logical order to form a story. It shows facts / data instead of discussing the results. Tables and Figures can be used but not repeating the same data in the same image, table and text. To further clarify the description, subtitles can be used.

Discussion is the basic explanation, relationship and generalization shown by the results. The description answers the research questions. If there are dubious results, then show them objectively. 
Desi Triana 1, Rusdinal 2, Jasrial 3, Susanti, Lusi 4. Pelayanan Tenaga Administrasi Sekolah Urusan Persuratan dan Pengarsipan Berbasis Teknologi Informasi di SMK se-Kota Payakumbuh

\subsection{Specification}

The Times New Roman typeface should be used throughout the manuscript, with the font size as exemplified in this writing guide. Spaces are singular and the contents of a text or script using left-right alignment (justified).

\subsection{Page Size}

The page size is A4 $(210 \mathrm{~mm} \times 297 \mathrm{~mm})$. The page margin is $25 \mathrm{~mm}$ up-down, left and right..

\subsection{Text Layout}

An easy way to create layouts is to use this guide directly.

\subsection{Headings}

Use style heading in this template directly. Style has been formatted in such a way as to provide suitable heading distance.

\subsection{Bullet dan Numbering}

Pada dasarnya disarankan untuk tidak menggunakan numbering (1,2,3..,a,b,c dst) dalam pembahasan naskahnya, ubah menjadi dalam bentuk kalimat. Hindari menggunakan Bullet/daftar berurut dengan simbol $* \sqrt{ }$ dan lainnya.

\section{Conclusion}

In conclusion there should be no reference. The conclusion contains the facts obtained. State the application possibilities, implications and speculations as appropriate. If necessary, give suggestions for further research..

\section{References}

Yuhefizar, Santosa B., Eddy I. K. P, and Suprapto Y. K, 2013, Combination of Cluster Method for Segmentation of Web Visitors. TELKOMNIKA, 11(1), pp. 207-214. doi: http://dx.doi.org/10.12928/telkomnika.v11i1.906.

Na`am J., Harlan J., Madenda S., and Wibowo E. P. 2016. Identification of the Proximal Caries of Dental X-Ray Image with Multiple Morphology Gradient Method. International Journal on Advanced Science, Engineering and Information Technology (IJASEIT), 6(3), pp. 343-346. doi:10.18517/ijaseit.6.3.827.

Na`am J., 2017. Edge Detection on Objects of Medical Image with Enhancement multiple Morphological Gradient (EmMG) Method. 4th Proc. EECSI. 23-24 Sep. 2017. Yogyakarta: Indonesia. doi=10.1109/EECSI.2017.82390 